\title{
Towards teacher professionalization for inclusive education: Reflections from the perspective of a socio-cultural approach
}

\author{
Francesco Arcidiacono $^{\text {al }}$ \& Aleksandar Baucal ${ }^{\mathrm{b}}$ \\ ${ }^{a}$ University of Teacher Education BEJUNE, Switzerland \\ ${ }^{b}$ University of Belgrade, Serbia
}

A common challenge in education in many European countries is related to inclusive education. It is probably the most important change in education for quite some time because it requires a comprehensive and deep transformation of mindset and practices with respect to all key aspects of education (e.g. policy making, teacher education, professional development of teachers, teaching/ learning practices, school leadership, family-school collaboration). The quest for inclusive education is also related to new tensions between different actors in education (teachers, students, parents, school principals, researchers and policy makers), since it disrupts foundation principles and ideas of dominant practices that are crystallized and normalized during a long history of segregated education of students with specific educational needs. Thus, it does not come as a surprise that the implementation of inclusive education is related to different opinions, hopes, concerns and reactions among key actors.

In this paper we are focusing on teacher education and teacher professionalization to reflect on these topics from the perspective of a socio-cultural approach. We believe that this view provides an appropriate conceptual lens for a better understanding of controversies and complexities related to the implementation of inclusive education, as well as for a reflection on teacher education, professional development and adequate support to teach. Following this line of thought, the paper is organized in three sections.

In the first one, we discuss the key assumption and the main concepts related to a socio-cultural approach within the overarching socio-cultural tradition. We will argue why the proposed view is an appropriate perspective to reflect on teacher training and professionalization in relation to inclusive education. We have chosen a specific approach because it assumes that the

University of Teacher Education BEJUNE, Ch. De la Ciblerie 45, 2503, Biel/Bienne, Switzerland; Francesco.Arcidiacono@hep-bejune.ch 
students' learning and development are socially and culturally constructed. This means that we might consider these processes and the related competencies as relational and contextual phenomena, and not as relatively stable/fixed, individual, and universal characteristics of students. Taking this perspective, the key question is not about what the child can or cannot do but concerns the kind of support and resources that should be provided to the child to make her or him capable to participate meaningfully in learning activities at school.

In the second section, we discuss some internationally recognized rights, duties, principles and values constituting the normative framework for inclusive education. This topic might surprise some readers because it can be seen as something less relevant to reflect on teacher professionalization. However, there are a few explanations to take it into account in this paper. Firstly, the current international framework for inclusive education is based on human rights and their application in education. Secondly, it is an important foundation for national policies aiming to ensure the children's rights in education. The national inclusive education policies set up the professional mission of teachers and provide a source for defining the competencies and practices that are needed to ensure adequate learning and developmental opportunities for all children. The last reason is related to the theoretical approach that we adopt in this paper: in fact, a discussion about teacher education and teacher professionalization from the socio-cultural perspective asks for recognizing the normative framework for inclusive education as a constitutive component of the topic.

In the third section, we discuss some elements concerning a model of inclusive education in Switzerland. We have chosen the case of Switzerland because we believe that an analysis of various forms of professional supports available for students and teachers, as well as the ways how teacher education is adapted to support inclusive education and teacher competencies for ensuring inclusiveness at school, could be relevant to think about current practices in other contexts, e.g. in Estonia. Moreover, Switzerland is an interesting case since it is not a unified education system. It is a complex configuration composed by 26 cantonal education arrangements, with different practices aiming to reach a common goal, that is to ensure similar opportunities for children with various educational needs, by taking into account different learning and developmental trajectories they might take and make.

The above-mentioned sections will allow us to discuss the need for a teacher professional training ensuring an inclusive education. The goal of the paper is to highlight the potential contribution of a socio-cultural approach in considering the value of special needs education, not only as a technical/professional issue but also as matter of core social values. 


\section{The key assumptions of socio-cultural approaches}

Socio-cultural approaches have a long history, but still they do not represent a unified theoretical and methodological approach. It is good to think about them as a "family" of different theories developed in educational sciences and psychology that share certain foundational assumptions and concepts. Consequently, we intend to present selected key concepts that in our view constitute a relevant framework for inclusive education and for professional education preparing teachers to become competent in ensuring quality in the education of all children.

Key founding ideas of the socio-cultural tradition had been formulated by Lev S. Vygotsky almost a century ago (Vygotsky, 1934/1986, 1978). The main assumption of his theory is that human beings are mediated by socio-cultural artefacts or tools - symbolical, social, material, and technological (Wertsch, 1991; Vygotsky, 1934/1986). It means that the relationship and the activities of a person do not reflect primarily stable characteristics of an individual or a situation, but cultural artefacts that mediate the mind and the activities of the person (e.g. Arcidiacono \& Baucal, 2019; Arcidiacono \& Pontecorvo, 2019; Baucal, 2012, 2013; Baucal \& Zittoun, 2013; Pontecorvo \& Arcidiacono, 2014).

The key implication of this assumption is that one needs to identify the cultural artefacts that mediate actor's mind and activities in order to understand his/her emotions, attitudes, beliefs, understandings, and practices. In other words, if an activity of two people would be mediated by different cultural artefacts, then their mindsets and practices would be different. Moreover, if the action of the same person would be mediated by different cultural artefacts in different occasions, then we could assume that his/her mindset and practice would be different. This assumption on the mediation of the human mind and activities is closely related to the idea that complex forms of human understandings and activities are socio-cultural by their nature and cannot be studied as individual, decontextualized, universal, and fixed phenomena, but as contextualized, relational, emerging and transforming phenomena (e.g. Baucal, Arcidiacono, \& Buđevac, 2011; Tartas, Perret-Clermont, \& Baucal, 2016). Based on the assumption of mediation, to be or not to be competent for a productive and meaningful participation in some social activity depends on availability, affordability and appropriation of suitable cultural artefacts and not on someone's inner stable and relatively fixed abilities. Therefore, when it comes to the teacher professionalization for inclusive education, the main goal is to ensure that teachers have the appropriate suitable professional mediation artefacts and tools enabling them to be competent in creating adequate learning opportunities for diverse children. 
The concept of mediation has been further developed by different authors (see Cole, 1996; Wertsch, 2007). An important conceptual refining is related to the distinction between explicit and implicit mediation. The first one refers to cases in which a person is aware of cultural artefacts mediating his/her mind and activities. An example is the experience of students in the education process. When a student needs to appropriate certain ways of thinking, speaking or doing, the teacher provides explicit psychological tools (concepts, key ideas, meanings) and additional support in the process of appropriation of new understandings and activities of the student. The implicit mediation is more typical in spontaneous everyday interactions, as well as in the informal education. In this case, the person is not aware of the cultural tools he/she is coming in touch with, nor how these tools are appropriated and how they mediate the person's mind and activity. It is a mediation that is not visible for the person at first sight, although he/she might become aware of the mediation tools through processes of reflection (Leijen, Pedaste, \& Lepp, 2019). In the case of teachers, this means that one needs to identify different explicit and implicit mediations to better interpret how and why teachers understand and perform their roles in the classroom (e.g. Radišić \& Baucal, 2016, 2018). Furthermore, it is important to map out and to analyze the cultural and professional tools that mediate in explicit ways the teachers' activities related to education (for example, the normative framework, the professional norms, the knowledge, and the practices).

Nowadays, the teacher profession is highly regulated at national and international level (for example, the UN Declaration of the Rights of the Child). The normative frameworks should also be taken into consideration when one applies the socio-cultural approach to education and teachers' professionalization. However, when it comes to specific forms of education (such as inclusion), teachers' activities might be mediated by various (implicit) shared beliefs, norms, attitudes and ideas that might support, but also prevent teachers to ensure inclusiveness of education (e.g. Daiute \& Kovac Cerovic, 2017; Stojanović \& Baucal, 2007). The identification of these mediators is very important, especially in the case of teachers opposing the implementation of inclusive education. For example, if a teacher appropriates the belief that "regular" education should serve only "regular" children who could be taught in a traditional way, then it does not come as a surprise that such teachers would feel uncomfortable when they need to teach children with special needs. In this case, he/she will not be interested in acquiring different professional practices that could create adequate opportunities to teach children with special needs. Therefore, a socio-cultural approach to education emphasizes the role 
of the cultural artefacts mediating teachers' minds and practices in explicit and implicit ways.

An additional key idea is related to the influential contribution of Engeström (1987) and his studies of institutional forms of human activities and professional practices. His work is relevant for a better understanding of teachers' participation in inclusive education, because he has shown that mediation in the professional context might be related to diverse professional and non-professional artefacts. These artefacts might be coherent and support professionals in performing their activities in a competent way, although they might be divergent and conflicting. Furthermore, he has suggested that one needs to take into consideration that different mediation tools are crafted by different communities and institutions and that they might reflect different values, principles and meanings. Consequently, it is very likely that they might be conflictual rather than harmonious. Thus, when one studies a human professional activity from a socio-cultural perspective, he/she needs to identify the origin of the different mediation tools to understand the complex and dynamic relations among them and how it might affect the human mind and activities in the professional context (Engeström, 2016; Fleer, 2016; Hedegaard, 2004). Since the teaching/learning processes are an excellent example of such kinds of activities, a socio-cultural approach to teacher education needs to pay special attention to various cultural and professional artefacts that mediate different teachers' activities (e.g. Radišić \& Baucal, 2018; Radišić, Baucal, \& Videnović, 2014). In this sense, it is important to understand how different principles, norms, knowledge, attitudes, beliefs, and identities of teachers are a result of the mediation of different artefacts that support or oppose each other and how they make teachers more or less capable to provide equal learning opportunities to all students.

In relation to the teacher professionalization for inclusive education, the key assumptions and concepts of a socio-cultural approach suggest that teacher education needs to create the opportunities for student teachers to appropriate a coherent set of mediation artefacts (principles, norms, values, knowledge, attitudes) that will make them able to ensure equal learning opportunities for all children. However, this is just a partial solution. The other aspect is related to the fact that schools, as the institutional frameworks for future teachers, also need to be aligned to enact some set of mediation artefacts supporting the inclusive education. This means that regulations, organizational structures, and institutionalized practices in schools need to be aligned to the mediation tools that future teachers can appropriate during their initial education. A sociocultural approach also implies that teachers need to have an appropriate system 
of professional support (within or/and outside the school), enabling them to practice inclusive activities in the classrooms, schools, and communities.

\section{A socio-cultural conceptualization of children with special needs}

The focus of the paper is on the teacher's professionalization related to inclusive education. However, from the perspective of a socio-cultural approach to inclusive education it is worth noting how it conceptualizes the notion of children with special needs. In this respect, Vygotsky (1993) was much ahead of his time, although he was limited by the terminology at the time (e.g. the word "defectology").

As already indicated, a socio-cultural approach assumes that human beings are mediated by symbolical, social, material and technological tools and that their competence to participate productively and meaningfully in a given social activity depends primarily on appropriated cultural artefacts that mediate them. Therefore, the main reason for a child to be able or disabled is related to the availability of enabling cultural artefacts and adequate opportunities to appropriate them. In this way, Vygotsky (1993) managed to create a common framework for both "normal" and "abnormal" development (referring to the language of his time), shifting the focus from the individual child to the sociocultural context and its capacity to provide suitable cultural context, artefacts and tools enabling all children to participate in relevant cultural activities (Gindis, 1995; Smagorinsky, Cole, \& Braga, 2017). Thus, a child with special needs (speaking in a contemporary way) is conceptualized by a socio-cultural approach as a child that needs different socio-cultural contexts (symbolical, material, and/or technological), specific cultural artefacts and tools, and forms of support by others to become capable to participate in relevant social and cultural activities. Consequently, the "inability" or the "disability" of a child reflect characteristics of the socio-cultural context and its failure to ensure suitable conditions for him/her to participate in socio-cultural activities, rather than the child's fixed individual characteristics. This is true even when there are "disabilities" or "disadvantages" in terms of physical, behavioral, emotional, cognitive, and social capacities, as well as for children living in poverty or being marginalized or discriminated within a society.

Following such unified conceptual framework, Vygotsky (1993) put forward a distinction between "primary disability" and "secondary disability." The primary disability refers to individual characteristics (biological, physical, emotional, cognitive) that might prevent or perplex them to participate in some social activity, while the secondary disability refers to a social exclusion, 
negative stereotypes and labeling, and lack of suitable social support preventing one to access and appropriation of enabling socio-cultural tools (Gindis, 1995; Smagorinsky, Cole, \& Braga, 2017; Vygotsky, 1993).

In the case of what we usually identify nowadays as special needs education, children with some kind of disability are seen mainly as those who are not able to participate in some social or educational activities (for example, a child is not able to go from a classroom to another office in the school by herself/ himself or a child is unable to pay attention during lessons). Following a sociocultural framework, instead of being focused on the primary disability, as it was labeled by Vygotsky (1993), the attention should be shifted to the secondary disability and how to prevent or overcome it. It means that the key question, from a socio-cultural perspective, would concern what kind of mediation artefacts (signs, tools, practical arrangements) need to be designed and offered to the child and what kind of support the teachers need to provide in order to enable children to become capable to participate in learning activities and to achieve learning objectives. For example, in a Serbian school in the classmates of a boy who was not able to go to the toilet by himself made colorful footsteps' stickers and put them in the corridor to mark the route from the classroom to the toilet. This arrangement was enough to make the boy independent when he needed to use the school's toilets (Baucal \& Pavlović Babić, 2016). Smagorinsky, Cole and Braga (2017) also provided a few good examples of successful implementation of a socio-cultural approach in ensuring adequate learning opportunities to some students who have been treated as "disabled." These are examples that nicely illustrate how a socio-cultural approach to inclusive education can change dominant understanding of what it means to be competent or not competent to participate in education activities and what should be done to overcome one's "disability."

This view on children's competencies has also an important implication to the typical practices of student's assessment. Through the use of socio-cultural lenses, if a child does not prove some competencies, it means that he/she does not have access to the appropriate tools and does not have the opportunity to appropriate them. In this way, the assessment will focus on the lack of available resources, rather than exclusively referring to the individual presumed disabilities. It is especially the case with children from a socially deprived background, lacking the advantages enjoyed by the majority of children. These children usually have a very low performance within a typical assessment setting. However, but when the setting is accommodated to their needs, they could perform quite differently (e.g. Nedić, Jošić, \& Baucal, 2015).

At the same time, a socio-cultural approach offers a different view to diagnostic categories. It suggests that different labels should not be interpreted and 
used as if they refer to some fixed inner individual trait or disability. Instead, different categories and labels associated to them should be taken as an indication that the children need specific kinds of support, arrangements and/or cultural artefacts to be capable to participate in specific social practices (e.g. Hjorne \& Säljö, 2004). Consequently, a diagnostic label should refer to a childcontext relationship and not to the exclusive individual child's characteristics.

A socio-cultural approach also promotes a similar framework for teacher competencies. It suggests that what makes teachers competent is not only related to their individual characteristics as professionals, but also to their social status, the beliefs about professionalization, the ideas about teaching/learning processes, training in inclusive education, the professional tools that are at their disposal as well as the collaboration, partnership and support promoted within the school. In other words, to be a competent inclusive teacher depends on many social, cultural and institutional components and not only on individual teachers' characteristics. Therefore, the key question would refer to what kind of support should be provided to the teachers to enable them to be competent to provide equal opportunities to all students, regardless of their abilities or disabilities. In this sense, teacher education should be designed in such a way as to provide teachers with the opportunity to appropriate specific sets of cultural artefacts (knowledge, attitudes, beliefs, principles, values, identities, and professional tools) to support all children in the learning process.

These socio-cultural assumptions and concepts remind us about the need of developing, at the European level, inclusive teaching/learning practices embodying the reflection competencies of teachers in the teaching/learning processes, their capacities to overcome challenges and to accommodate their practices to the specific educational needs of their students (Passiatore et al., 2019). To attend to the well-being of learners means to take responsibility for meeting the needs of all children, to ensure a positive ethos and to establish good relationships. These assumptions require a collaboration among different actors (teachers, children, professionals, parents) to plan an engaging curriculum aimed at meeting the diverse needs of learners and promoting equality and human rights.

In this sense, a socio-cultural approach invites us to use a variety of inclusive opportunities to appropriate the aims of learning, the learners' status and their abilities or potential of development. It is only through an approach promoting the engagement and the possibility to explore the broader meaning of competencies that teachers and all the social actors can "become aware of their own identities and value positions, and of their crucial role in preparing and forming future citizens for a democratic society" (Moran, 2009, p. 8). 


\section{Special needs education: From prescriptive elements to an inclusive approach}

In order to articulate the relationship between teacher training and professionalization, inclusive education and curricula aiming at enhancing the teachers' competencies and supporting their practices, two different but interconnected elements should be considered. Firstly, the assumption that teacher education is a way to contribute to inclusive societies. In particular, we are aware that all the children have similar needs for relatedness, autonomy and competence when engaging in learning (Ryan \& Deci, 2000). For this reason, we intend to show how a socio-cultural approach constitutes a way to foster teacher professionalization and inclusive education. To clarify this position, we will refer to some historical and sociological elements about inclusive education. In fact, this excursus seems necessary to understand the trajectory of special needs education and the steps adopted to train teachers in this domain.

Secondly, we recognize that the issue of teacher education is high on the policy agenda across Europe, and globally. It is recognized that the role of teachers and special needs education in moving towards a more inclusive system. In late 2007, representatives of the member countries of the European Agency for Special Needs and Inclusive Education discussed several issues relating to the topic of teacher education for inclusion, which had been prioritized within member countries. Different questions arise on how can teachers be prepared via their training to be inclusive, prepared to take responsibility for all learners in their classes and to be supported to build capacities to do so.

Let's consider the two above-mentioned elements by clarifying the place of special needs education and its socio-historical evolution. The term "inclusion" refers to a far wider range of learners vulnerable to exclusion than those identified as having special educational needs. The UNESCO-IBE (2008) highlighted that "inclusive education is an on-going process aimed at offering quality education for all while respecting diversity and the different needs and abilities, characteristics and learning expectations of the students and communities, eliminating all forms of discrimination" (p. 3). However, a key issue raised in literature is that of terminology. For example, Ainscow and colleagues (2006) developed a typology of different ways of thinking about inclusion, such as inclusion as a concern with disabled students and others categorized as having special educational needs, as a response to disciplinary exclusion, in relation to all groups being vulnerable to exclusion, as a need to developing the school for all, or as a principled approach to education and society. At the same time, even the term "special needs education" also contributed to enrich the debate about 
definitions assumed in different systems, with its connection to discussions primarily about the placement of learners in special or mainstream schools. Norwich (2010) stated that the term special educational needs was introduced to move away from deficit categories, to increase the focus on what is required to provide opportunities and support learning. However, despite increased attention to the learning environment, a focus on negative labelling often remains. Twenty years ago (OECD, 2000), it has been recognized that the terms disabilities or difficulties (as socioeconomic, cultural or linguistic factors) refer to a plethora of elements, such as the right to receive special education and to have specialist support (e.g., language or psychomotor therapists).

Historically, the development of a restricted or hazarded inability to meet the usual school standards, as well as the difficulty in social competence, learning and performing abilities, have contributed to build a general discussion at different levels. We intend to restate some of the steps that contributed to create a common idea of special needs education, although they have determined, in some cases, a list of elements that mostly remain as prescriptions.

In 1989, the UN Convention on the Rights of the Child, followed by the UN Convention on the Rights of Persons with Disabilities, tried to set a framework related to the full development of the human potential and diversity, as well as the development of personality, talents and creativity, enabling them to participate in a free society. Article 24 of the second Convention states that inclusive education provides the best educational environment for children with disabilities and helps to break down barriers and challenge stereotypes. In addition, the Convention emphasizes the need to train all teachers to work within inclusive classrooms, recognizing the increasing diversity in today's schools. These indications have been inspired by the UNESCO Salamanca Statement in 1994, highlighting the role of interaction within specific environments. In this regard, the OECD (2007) indicated two dimensions of equity in education that are fairness, which implies ensuring that personal and social circumstances should not be an obstacle to achieving educational potential, and inclusion, which includes to guarantee a basic minimum standard of education for all. An inclusive education is then desirable because there is a human rights imperative for people to be able to develop their capacities and participate fully in society, to reduce socially and economically high costs (for health, income support, child welfare and security), and to challenge the questions posed by the increased migration (in terms of social cohesion, integration of minorities, equity in education, and trust). As highlighted by Barton (1997), "inclusive education is about responding to diversity; it is about listening to unfamiliar voices, being open, empowering all members and about celebrating difference in dignified ways" (p. 234). 
These elements allow us to consider the challenges deriving from a societal pressure for better output from schools versus the presence of vulnerable pupils, as well as the heterogeneity in teacher education. As already indicated these aspects are viewed from a socio-cultural approach to understand the place of special needs education in the teachers' training. This issue also implies a reflection on other aspects, such as the eligibility procedures to identify requirements for inclusion, and where and why children are labelled as unable to participate in regular education, for instance, because of the severity of their impairment or through criteria indicated in lists of defects. A major question also concerns the dissatisfaction in perceiving individuals' differences rather than population diversity, namely the focus on impairments rather than functioning, and the promotion of segregation rather than inclusion. Naukkarinen (2010) pointed out that teachers must see learners as having "multiple intelligences and learning styles along many dimensions, rather than belonging to a category" (p. 190). This view invites us to develop a continuum of support rather than a model based on categorization. The emphasis on participation in learning is relevant and can contribute to move away from the withdrawal of learners from the classroom, as exclusive way to work with specialists aiming at "fixing" difficulties. Such a model of thinking can lead to an increase in referrals to special education (Pijl, 2010), as well as a teachers' lack of confidence and competence in meeting the needs of diverse learners.

According to Sliwka (2010), this shift from homogeneity to diversity can contribute to acknowledge the fact that difference is not a challenge to be dealt with, but an asset, an opportunity. The paradigm of diversity can open the space to consider differences as resources for learning and development. Indeed, inclusive educational policies need to be associated with different broader values and principles, such as quality, equity, social justice, democracy, and participation (Arnesen, Allen, \& Simonsen, 2009). These elements will be considered in the final section of this paper as aspects to be promoted within a socio-cultural approach in education.

\section{Practices in promoting inclusion during teacher education: The example of Switzerland}

Many countries have provided examples of inclusive practices in teacher education. We focus here on the specific context of Switzerland, because it refers to a particular trajectory in connecting teacher education and inclusion. Firstly, we will present some elements of contextualization to provide useful details about the general background. Then, we will focus on teachers' curricula related to 
the promotion of special needs education within an inclusive society, inspired by a socio-cultural approach.

In Switzerland, the cantons are responsible for the organization of special needs education, as they are for education in general ${ }^{2}$. There are special forms of schooling for pupils who cannot meet the usual school standards, or who need special educational programs to do so. Compulsory education also applies to pupils with visual and hearing impairments, physical, learning and intellectual disabilities, speech and behavioral disorders. Early childhood intervention in Switzerland is mostly family-based. Measures can start at birth or in the very early years, before the child starts school. Either the early intervention specialist(s) come(s) to the child's home, or the parents bring the child to the early intervention service. They sometimes work with small groups of children. In addition, children with more severe problems can receive residential care in a specialized institution (e.g. a boarding house) on a temporary basis or for a longer period. There are over 100 early intervention services ensuring coverage of the whole country. Mostly, they are delivered by generalists experienced in dealing with different problems and impairments. In recent years, the number of freelance early intervention specialists has increased. Early intervention services are in some cases privately managed (e.g. by parents' associations), while in other cases they are managed by public bodies (e.g. local authorities or cantons).

Specialized education is provided for children attending special schools or special classes linked to mainstream schools. There is also integrated schooling with support from a special school. Special schools cater for children presenting some developmental delays and needing particular facilities connected to intellectual or physical disabilities, severe behavioral disorders and hearing, speech or visual impairments. Concerning the special classes, the provision of education is linked to mainstream schooling. There are smaller classes at primary level (generally no more than 14 pupils, adapted curriculum) and practical classes at the lower-secondary level (practical activities, orientation, reduced curriculum). These classes consist of a substantial proportion of pupils with behavioral problems and pupils with learning difficulties. About a third of the pupils in these classes are girls, while the proportion of pupils from ethnic minorities is higher than those of Swiss nationality. However, since 2015 the number of pupils in special classes has diminished considerably. This has been

In 2017-2018, there were more than 1.4 million pupils and students in Switzerland, representing almost a fifth of the country's population. Roughly, half of people in education are women and almost a third are of foreign nationality. $67 \%$ of people in education are in compulsory schooling, $18 \%$ at upper secondary level and 15\% at tertiary level. 
the result of a long process pursuing the goal of inclusive education, instead of maintaining models of segregation or partial integration.

Through inclusive schooling, children and young people with special needs who are integrated into mainstream schooling may be supervised by a support teacher, who is involved in the class for a certain number of hours, depending on a pupil's needs. At kindergarten, in certain cantons, children may continue to benefit from early intervention measures. In such cases, an early intervention specialist, who is mainly involved in the child's family environment but also makes occasional visits to the kindergarten, supervises them. Primarily, the legal provisions in force in each canton govern integration into mainstream schooling. Inclusion, rather than attendance at a special school, is the preferred alternative for pupils with less severe disabilities. Children with special educational needs who are included into mainstream schools also benefit from individual special education provisions. These facilities are delivered by visiting services, most frequently as counselling and educational supports (speech therapy, psychomotor therapy and early intervention). When locally available resources are insufficient, additional resources for training and education must be provided. These are known as enhanced individual measures. They differ from ordinary measures because they are of long duration, more intense, teachers are more specialized, and intend to have a significant impact on the child's daily conduct, as well as his/her social environment and life path. A primary cycle is currently being tested in a number of pilot projects in some of the German-speaking cantons of Switzerland. Sometimes, private schools also offer this type of education. Children aged from 4 to 8 are taught together in a single class and this primary cycle may last between 3 and 5 years. This arrangement involves a great deal of differentiation, taking into account the specific needs of each child. For this reason, it facilitates the inclusion of pupils with special educational needs. Compared with special needs education at the primary and lower-secondary levels, preparation for vocational activities and training of young people with special needs are less well developed. Opportunities for further training and employment depend very much on the nature of a person's need. Pupils with special educational needs attending higher schools are mostly affected by physical disabilities. They are regularly included into mainstream schools.

In most cantons, the school psychological services, child and adolescent psychological services, or other specialists are responsible for the decision as to whether the person with special needs will attend which type of school. The intention of the evaluation procedures is not for individual characteristics (e.g. an impairment) to trigger measures, but for the actual needs to be determined, based on transparent developmental and educational goals. The procedure 
enables these school services to make a comprehensive, multi-dimensional evaluation and it constitutes an initial basis for targeted support in the intended setting. The evaluation procedure is applied if the locally available resources for special needs education are insufficient and additional resources have to be provided for education and training. The introduction of the evaluation procedure dispenses with the disability insurance criteria, which previously were based primarily on limits. Now, when determining requirements, attention is paid to the developmental and educational goals of the children.

The inclusion of people with special educational needs into mainstream school is central in Switzerland. Most cantons have developed concepts, regulations and guidelines to offer corresponding provisions. On the federal level, the law on equal rights for people with disabilities recommends that the cantons promote inclusion. The change from federal to cantonal authority at the beginning of 2008 may threaten the level of provision for special needs education, but is also a chance to promote inclusion. In fact, the cantons will have more flexibility to establish models of schooling matching their demographic and geographic structure and therefore develop inclusive forms of special needs education. In line with other countries, parental pressure towards inclusion is growing. Generally, less densely populated areas have, due to their geographical situation, more inclusive offers than other parts of Switzerland, for example by offering teacher and pupil a support in mainstream schools, with the result that there is no segregation for the less severe forms of special needs. These principles regarding inclusion and special needs education are stated in the national recommendations (COHEP, 2008) that recognize an important issue: mainstream schools are the place for inclusive learning of all children and their teachers in the mainstream have to act in a professional way in diverse inclusive educational settings.

This synthetic and partial view does not account for the multiple different situations that can be recognized within a federal country. However, we think that the experience observed in Switzerland is a paradigmatic example of how inclusion can bear fruit from a socio-historical process, involving different actors having a common goal and a shared approach. In our view, a socio-cultural approach can help to make visible the complexity of the issue concerning the inclusive learning of all children and can contribute to improve the teachers' professionalization for diverse inclusive educational settings. In fact, a socio-cultural approach promoting the idea that deficit is not within a child in line with what has been already sustained by the research traditions of disability studies in education (e.g. Connor et al., 2008). 
More particularly, a socio-cultural approach can be complementary to disability studies in education ${ }^{3}$ in deepening and understanding of the experiences of people with special needs, across diverse cultures and within various historical contexts. In fact, despite a multiplicity of scholarly perspectives, a pivotal and unifying perspective of disability studies concerns the fact that disability is a social construct (Taylor, 2006). This element is related to the approach we promote in the present paper. Both approaches pay attention to the social, cultural, historical, and individual understandings of special needs education and work to create and sustain inclusive and accessible schools.

In the following sections of the paper, we intend to focus on the other side of the issue: the logics of teacher education and the organization of trainings offered to professionals acting within an inclusive society.

\section{Teacher education for an inclusive school}

Although the Bologna reforms of higher education in Europe have led to growing formal consistency, the length of the initial teacher education courses currently varies between 2 and 5.5 years. The majority of countries however require a Bachelor's degree course with a minority extending this to a Master's program. This is clearly a positive development in terms of both the status of the teachers and the increased time for relevant study and practice - bearing in mind that more inclusive approaches cannot be achieved simply by bolting on additional content. Two main models of teacher education are usually proposed: one in which both the school subjects and the knowledge and skills needed to teach them are combined; another in which education in a higher education institution concerns one or more school subjects, followed by separate courses involving pedagogy, didactics, classroom practice, and so on. Even in countries where teaching is a high-status occupation and there is greater competition for places, there is no guarantee that the most able candidates in academic terms will become the most effective teachers. Account needs to be taken of people's prior experiences of working with learners with diverse needs, as well as their reflections upon these, and their dispositions towards inclusive practices. For these reasons, in most countries, courses consist of a combination of subjects and periods of teaching practice.

In Switzerland, as the example selected for the present paper, the model of education about one or more school subjects is followed by an additional program on pedagogy, didactics and classroom practices, as well as the

In this paper, we are referring to disability studies in a broad sense. For a review of traditions of disability studies and critical disability studies, see Meekosha and Shuttleworth (2009). 
combination of training at university and teaching activities at school. More particularly, concerning the field of special needs education, the national recommendations (COHEP, 2008) intend to go beyond a traditional view of disability, by including different aspects, related to special needs education, diversity, teaching in inclusive settings, collaborative practices, school development and knowledge of the organizational structures towards inclusion. These contents should cover at least $5 \%$ of all teacher programs, both in primary and secondary education. The main idea is to ensure a basic special needs education for all teachers, to consider attitudes and modalities to differentiate teaching practices, and to sustain the collaboration among professionals (teachers, speech therapists, psychomotricity specialists, and other educators).

The Master's program in special needs education aims at developing a teacher professionalization for being able to evaluate specific needs and to adopt the related teaching practices, in regular or special schools, as well as to become a school consultant for different educational issues. The curriculum concerns a series of skills related to the capacity of establishing a diagnostic evaluation, implementing specialized teaching projects, promoting interdisciplinary collaborations with other specialists, and working in specialized school environments. In addition, teachers are expected to act as consultant and supportive professionals in special needs education. They are trained to develop a theoretical reflection with scientific bases for taking teaching initiatives, to reflect on personal, social and professional skills, as well as to lead qualitative and/or quantitative research projects. The domains covered by the curriculum also includes other topics, such as inclusion, handicap, cognition, neurological development, communication, intelligence deficiency. These aspects are operationalized through theoretical courses, practical training at school, research activities, and different opportunities for taking a reflexive posture. The role of practical training is crucial in the curriculum. In the course of a 3-years program, teacher students are involved in 28 days of employee's time for internship and 30 days for observations in schools or specialized institutions. This process is completed by a tutoring stage including 24 sessions of 3 hours (individually and in small groups). During the $1^{\text {st }}$ year of the program, the focus is on the evaluation of their own professional competencies, through the analysis of videos related to teaching/learning activities. During the $2^{\text {nd }}$ year, a co-evaluation is organized with a supervisor. The evaluation assumes the same character. The $3^{\text {rd }}$ year aims at ensuring a tutoring and a co-evaluation process with peers. A systemic interview is conducted and the final evaluation includes a written text about the education training.

These activities are designed according to the principles of a socio-cultural approach promoting not only knowledge about key-aspects of teaching and 
practices, but also a more global capacity to consider the context, the available resources and tools, as well as the potential of each student within various social environments. In this sense, such a socio-cultural approach contributed to identify pertinent politics of the Swiss education system. In designing the actual programs of teacher education, stakeholders have benefitted from the contributions developed within the socio-cultural tradition of research. The collective participation and the acknowledgement of the key-role played by social relations and cultural meanings have determined an awareness of the responsibilities of educational institutions to children with special needs. Teacher education in Switzerland has also taken on board different disciplines and involved in designing a system in which special education is interdisciplinary and programs engage with various perspectives.

\section{Discussion and conclusion}

The inclusive education from a socio-cultural perspective is not only a professional issue, but it is a matter of core social values. If citizens who constitute and who are owners of the society have opted for an inclusive community, it is up to educational specialists to use their knowledge and skills to support it. The ultimate goal for the development of children is to become full members of the society: in other words, to belong, to be active members and to be competent in their professional fields (Biesta, 2009). Consequently, an inclusive society requires an inclusive education, because it is difficult to imagine that a child educated in a segregated environment can overnight become an integrated citizen. To provide the access to adequate socio-cultural tools, as well as learning opportunities and supports needed for the appropriation of these artefacts, it is essential to become a competent citizen. For these reasons, we are convinced that it is necessary to propose learning processes within appropriate educational contexts. In this sense, inclusive education does not exclude that some learning activities might be organized in specific designed settings, but it means that this should be a temporary solution aiming to providing additional support to students with an ultimate goal to enable them to participate fully in regular education.

As already indicated, a socio-cultural approach highlights that human being competencies rely on the tools that are appropriated by people in different settings. Consequently, it excludes education that happens mostly in segregated settings, because they can prevent the children integrating the tools based on which they might be functionally equivalent to other people. In this sense, the key question is not what the child is not able to do, but what kind of tools and 
support the child needs in order to become a competent and active citizen. In education, there is never a single method, setting or goal that can be identified as superior over others: it is always about finding the best solution in a complex set of conditions and with the (often limited) available resources.

Children with special educational needs are not a pre-existing special group with pre-defined special demands. Considering overall human functioning, we are convinced that there is more sameness of functioning with all children than differences. An education system that respects the idea of a continuum of functioning among children should offer the appropriate educational services, because all children have similar needs for relatedness, autonomy and competence when engaging in learning. The participation in education therefore should be the first and most important concern when planning changes in educational settings and services.

Several countries have recently undergone or are currently undergoing significant changes in education policies and curricula. Some of the factors that prompt these situations are related to the concern of under-achievement (as highlighted by national assessments and international comparisons such as PISA), to an increasing disaffection among learners (and early school dropouts), to the issues of changing demographics (increasing the number of learners from diverse cultural and linguistic backgrounds), and a need of revising curricula (to promote social cohesion or to address the effects of the current social and economic climate).

To implement policies and practices supporting a move towards greater inclusion, countries need to recognize the importance of underpinning values and positive school and community cultures. In many countries, the current existence of separate provision for some groups of learners inevitably influences the education of teachers: curriculum and assessment, together with pedagogy, must be designed to facilitate the achievement of learners with diverse needs, ensuring that these needs are also addressed through a close collaboration among professionals within the school, as well as with other agencies. The examples that have inspired our work are useful cases to reflect on these elements.

In conclusion, we highlight that the benefits of increasing inclusion, linked to other priorities such as social justice and community cohesion, can be longterm investments for the educational system, likely to represent a more effective use of resources than short-term initiatives, often designed to close gaps or support certain marginalized groups. A vision of a more equitable education system requires teachers equipped with different competencies adequate to meet diverse needs. We are convinced that a socio-cultural approach should be an inspiring perspective to develop this view and to promote reflections about 
inclusion and education. Further research will contribute to this challenge and will ensure a high-quality system for all learners, based on the promotion of adequate teacher trainings in special needs education.

\section{References}

Ainscow, M., Booth, T., Dyson, A., Farrell, P., Frankham, J., Gallannaugh, F., Howes, A., \& Smith, R. (2006). Improving Schools: Developing Inclusion. London: Routledge.

Arcidiacono, F., \& Baucal, A. (2019). Le interazioni sociali nell'apprendimento [Social interaction in learning]. Rome: Carocci.

Arcidiacono, F., \& Pontecorvo, C. (2019). On materiality: Home spaces and objects as expanding elements of everyday experiences. Forum: Qualitative Social Research, 20(3), art. 5. http://dx.doi.org/10.17169/fqs-20.3.3165

Arnesen, A., Allen, J., \& Simonsen, E. (Eds.) (2009). Policies and practices for teaching socio-cultural diversity. Concepts, principles and challenges in teacher education. Strasbourg: Council of Europe.

Barton, L. (1997). Inclusive education: Romantic, subversive or realistic. Inclusive Education, 3(1), 231-242. https://doi.org/10.1080/1360311970010301

Baucal, A. (2012). Scaffolding by design: Co-construction through interaction with culturally structured environment. In A. Baucal \& J. Radišić (Eds.), Patchwork. Learning Diversities - conference proceedings (pp. 71-79). Belgrade: Institute of Psychology.

Baucal, A. (2013). Two instead of one ZPD: Individual and joint construction in the ZPD. In S. Phillipson, K. Ku \& S. Phillipson (Eds.), Constructing educational achievement: A sociocultural perspective (pp. 161-173). London: Routledge.

Baucal, A., Arcidiacono, F., \& Buđevac, N. (2011). Reflecting on different views of social interaction: Ex-planatory and analytic perspectives. In A. Baucal, F. Arcidiacono \& N. Buđevac (Eds.), Studying interaction in different contexts: A qualitative view (pp. 233-251). Belgrade: Institute of Psychology.

Baucal, A., \& Pavlović Babić, D. (Eds.) (2016). Prepoznaj, promovši i proširi - priče o uspešnim školama [Identify, Promote, and Scale up - Stories on Successful Schools]. Belgrade: Institute of Psychology.

Baucal A., \& Zittoun T. (2013). Religion as dialogical resource: A socio-cultural approach. Integrative Psychological \& Behavioral Science, 47(2), 207-219. https://doi.org/10.1007/s12124-013-9229-z

Biesta, G. (2009). Good education in an age of measurement: on the need to reconnect with the question of purpose in education. Educational Assessment, Evaluation and Accountability, 21(1), 33-46. https://doi.org/10.1007/s11092-008-9064-9

COHEP. (2008). Analyse und Empfehlungen: Heilpädagogik in der allgemeinen Lehrerinnen- und Lehrerbildung [Analysis and recommendations: Special education in general and teacher education]. Arbeitsgruppe Heilpädagogik der COHEP, December 2008.

Cole, M. (1996). Cultural Psychology. Cambridge: Harvard University Press. 
Connor, D. J., Gabel, S. L., Gallagher, D. J., \& Morton, M. (2008). Disability studies and inclusive education. Implications for theory, research, and practice. International Journal of Inclusive Education, 12(5-6), 441-457. https://doi.org/10.1080/13603110802377482

Daiute, C., \& Kovac Cerovic, T. (2017). Minority Teachers Roma in Serbia: Narrate Education Reform. Belgrade: Institute of Psychology.

Engeström, Y. (1987). Learning by Expanding: An Activity-Theoretical Approach to Developmental Research. Cambridge: Cambridge University Press.

Engeström, Y. (2016). Studies in expansive learning: Learning what is not yet there. Cambridge: Cambridge University Press.

Fleer, M. (2016). The Vygotsky project in education - The theoretical foundations for analysing the relations between the personal, institutional and societal conditions for studying development. In D. S. P. Gedera \& P. J. Williams (Eds.), Activity Theory in Education Research and Practice (pp. 1-18). Rotterdam: Sense. https://doi.org/10.1007/978-94-6300-387-2_1

Gindis, B. (1995). The social/cultural implication of disability: Vygotsky's paradigm for special education. Educational Psychologist, 30(2), 77-81. https://doi.org/10.1207/s15326985ep3002_4

Hedegaard, M. (2004). A cultural-historical approach to learning in classrooms. Outlines, 6(1), 21-34.

Hjorne, E., \& Säljö, R. (2004). „There is something about Julia.“ Symptoms, categories, and the process of invoking attention deficit hyperactivity disorder in the Swedish school: A case study. Journal of Language, Identity \& Education, 3(1), 1-24. https://doi.org/10.1207/s15327701jlie0301_1

Leijen, Ä., Pedaste, M., \& Lepp, L. (2019). Teacher agency following the ecological model: How it is achieved and how it could be strengthened by different types of reflection. British Journal of Educational Studies. https://doi.org/10.1080/00071005.2019.1672855

Meekosha, H., \& Shuttleworth, R. (2009). What's so 'critical' about critical disability studies? Australian Journal of Human Rights, 15(1), 47-75. https://doi.org/10.1080/1323238X.2009.11910861

Moran, A. (2009). Can a competence or standards model facilitate an inclusive approach to teacher education? International Journal of Inclusive Education, 13(1), 45-61. https://doi.org/10.1080/13603110701273675

Naukkarinen, A. (2010). From discrete to transformed? Developing inclusive primary school teacher education in a Finnish teacher education department. Journal of Research in Special Educational Needs, 10(1), 185-196. https://doi.org/10.1111/j.1471-3802.2010.01168.x

Nedić, J., Jošić, S., \& Baucal, A. (2015). The role of asymmetrical interaction in the assessment of nonverbal abilities of children from the Drop-in center. Inovacije $u$ nastavi - časopis za savremenu nastavu, 28(3), 189-206.

https://doi.org/10.5937/inovacije1503189N

Norwich, B. (2010). A response to 'Special Educational Needs: A New Look' In L. Terzi (Ed.), Special Educational Needs: A New Look. London: Continuum.

Organization for Economic Co-operation and Development. (2000). Special Needs Education Statistics and Indicators. Paris: OECD. 
Organization for Economic Co-operation and Development. (2007). No more failures: Ten steps to equity in education. Paris: OECD.

Passiatore, Y., Pirchio, S., Carrus, G., Maricchiolo, F., Fiorilli, C., \& Arcidiacono, F. (2019). Intercultural practices and inclusive education in Europe: Can migration be a resource for individual and societal development? European Journal of Psychology of Education, 34(1), 209-224.

https://doi.org/10.1007/s10212-017-0360-y

Pijl, S. J. (2010). Preparing teachers for inclusive education: Some reflections from the Netherlands. Journal of Research in Special Educational Needs, 10(1), 197-201. https://doi.org/10.1111/j.1471-3802.2010.01165.x

Pontecorvo, C., \& Arcidiacono, F. (2014). Social interactions in families and schools as contexts for the development of spaces of thinking. In T. Zittoun \& A. Iannaccone (Eds.), Activity of thinking in social spaces (pp. 83-97). New York: Nova Science Publishers.

Radišić, J., \& Baucal, A. (2016). „What about when the majority is excluded?“ A critical eye on language and math classrooms in Serbia. In A. Surian (Ed.), Open Spaces for Interactions and Learning Diversities (pp. 167-178). Rotterdam: Sense Publishers. https://doi.org/10.1007/978-94-6300-340-7_12

Radišić, J., \& Baucal, A. (2018). Teachers' reflection on PISA items and why they are so hard for students in Serbia. European Journal of Psychology of Education, 33(3), 445-466. https://doi.org/10.1007/s10212-018-0366-0

Radišić, J., Baucal, A., \& Videnović, M. (2014). Unfolding the assessment process in a whole class mathematics setting. Psihološka istraživanja, 17(2), 137-158.

https://doi.org/10.5937/PsIstra1402137R

Ryan, R. M., \& Deci, E. L. (2000). Self-determination theory and the facilitation of intrinsic motivation, social development, and well-being. American Psychologist, 55, 68-78. https://doi.org/10.1037/0003-066X.55.1.68

Sliwka, A. (2010). From homogeneity to diversity in German education. In Educating Teachers for Diversity - meeting the Challenge. Paris: OECD.

Smagorinsky, P., Cole, M., \& Braga, L. W. (2017). On the complementarity of cultural historical psychology and contemporary disability studies. In I. Esmonde \& A. N. Booker (Eds.), Power and privilege in the learning sciences (pp. 70-92). New York: Routledge.

Stojanović, J., \& Baucal, A. (2007). Equal Access to Quality Education for Roma: Serbia. In Equal Access to Quality Education for Roma. Budapest: Open Society Institute - EU Monitoring and Advocacy Program.

Tartas, V., Perret-Clermont, A.-N., \& Baucal, A. (2016). Experimental micro-histories, private speech and a study of children's learning and cognitive development. Infancia y Aprendizaje, 39(4), 772-811. https://doi.org/10.1080/02103702.2016.1221055

Taylor, S. J. (2006). Before it had a name: Exploring the historical roots of disability studies in education. In S. Danforth \& S. L. Gabel (Eds.), Vital questions facing disability studies in education (pp. xiii-xxiii). New York: Lang.

UNESCO-IBE. (2008). Conclusions and recommendations of the 48th session of the International Conference on Education (ED/BIE/CONFINTED 48/5) Geneva: UNESCO IBE. (retrieved at: http://www.ibe.unesco.org/en/ice/48th-ice-2008/conclusions-and-recommendations.html). 
United Nations. (1989). Convention on the Rights of the Child. New York: United Nations.

Võgotski, L. S. (1934/1986). Thought and Language (transl. edited by A. Kozulin). Cambridge: The MIT Press.

Võgotski, L. S. (1978). Mind in Society: The Development of Higher Psychological Processes. Cambridge: Harvard University Press.

Võgotski, L. S. (1993). The fundamentals of defectology (abnormal psychology and learning disabilities). In R. W. Rieber \& A. S. Carton (Eds.), The collected works of L. S. Vygotsky - Volume 2: The fundamentals of defectology (pp. 29-51). New York: Plenum.

Wertsch, J. V. (1991). Voices of the Mind. Cambridge: Harvard University Press.

Wertsch, J. V. (2007). Mediation. In H. Daniels, M. Cole \& J. V. Wertsch (Eds.), The Cambridge Companion to Vygotsky (pp. 178-192). Cambridge: Cambridge University Press. https://doi.org/10.1017/CCOL0521831040.008 